\title{
Capoeira Angola, corpo e ancestralidade: por uma educação libertadora
}

\author{
Sara Abreu da Mata Machado* \\ Rosângela Costa Araújo ${ }^{* *}$
}

\begin{abstract}
Resumo
No presente artigo apresentamos reflexões sobre a Capoeira Angola como uma cultura de matrizes negras e africanas no Brasil e como uma práxis educativa transformadora e libertadora. Destacamos alguns princípios compreendidos como fundamentais à cosmo visão afro-brasileira para pensarmos em formas de educação mais inclusivas e voltadas para o crescimento humano integral, como: Comunidade, Ancestralidade, Oralidade, Ritualidade, Ética e Corporeidade. Buscamos, com essa reflexão, construir elementos de análise sobre os limites e potencialidades da Capoeira Angola para a construção da autonomia e emancipação dos sujeitos, e formadora na relação com a diversidade cultural. Essas reflexões foram frutos de nossa pesquisa de mestrado, que tratou do trabalho do grupo Nzinga de Capoeira Angola com crianças e jovens da comunidade quilombola do Alto da Sereia, em Salvador/BA.

Palavras-chave: Capoeira Angola, Ancestralidade, Educação, Diversidade.
\end{abstract}

\section{Capoeira Angola, corporality and ancestry: for a freedom education}

\begin{abstract}
In this article we present reflections about Capoeira Angola as a culture of black and African heritage in Brazil and as a transforming and liberating educational praxis. We emphasize some principles understood as fundamental to the African-Brazilian worldview to think of ways to add more inclusive education and focused on integral human growth, such as: community, ancestry, orality, rituality, ethics and corporality. We seek with this reflection to build analytical elements about the limits and potentialities of Capoeira Angola to promote the autonomy and empowerment of people, as well as promoting a learning relationship with the cultural diversity. These considerations are the result of our master's research, which dealt with the work of the Capoeira Angola group Nzinga with children and young people in a quilombo community called Alto da Sereia, in Salvador, Bahia, Brasil.

Keywords: Capoeira Angola, Ancestry, Education, Diversity.
\end{abstract}

\begin{abstract}
Abrindo a Roda
"Capoeira Angola é mandinga de escravo em ânsia de liberdade” (Mestre Pastinha) ${ }^{l}$.
\end{abstract}

A Capoeira Angola, uma das mais importantes tradições culturais de matriz africana no Brasil, configura-se, atualmente, como uma filosofia de vida, uma forma de ver o mundo, que se atualiza e se insere no jogo político, na luta por reconhecimento. Os movimentos da capoeira nos permitem obter e criar visões de mundo dos mais diversos ângulos e posições.

Aprender os movimentos da capoeira não se limita a aprender a jogar em uma roda de capoeira. A Capoeira Angola é um jogo de desafios e inversões, mais que certezas. A Capoeira Angola tem também estrutura, mas que, ao invés de limitar, pode ter o sentido de libertar, como nos diz Eduardo Oliveira (2007a, p.182): “A capoeira angola é uma totalidade aberta (alteridade) e tem como estrutura a ancestralidade (sagrado). A ancestralidade não é um conjunto rígido de sanções morais, mas um modo de vida". A capoeira angola é um modo de vida, que se fundamenta na ancestralidade e "que só existe por causa do mistério. Lógica diferencial porque inventiva" (OLIVEIRA, 2007a, p. 181).

A palavra "educação" não existia nas línguas tradicionais africanas, como explica Petronilha Gonçalves e Silva (2003) ao dizer que, para os africanos e afro-descendentes, o termo educar-se tem um sentido mais amplo: tornar-se pessoa, traduzido como aprender a própria vida. Em sua dimensão educativa, o jogo da capoeira ensina e reflete as formas de se relacionar com o outro e consigo mesmo. Assim, os ensinamentos da capoeira estão intimamente ligados ao processo de formação humana dos sujeitos, estimulando a constante auto-reflexão e auto-avaliação sobre, por exemplo, a relação com nossa família, com a(s) comunidade(s) a que pertencemos (de capoeiristas ou não), com nossa sociedade, com a humanidade,

\footnotetext{
*Doutoranda pelo Doutorado Multi-institucional e Multidisciplinar em Difusão do Conhecimento, UFBA, Salvador. Endereço eletrônico: sara.abreu@gmail.com

**Professora Dra. da Universidade Federal da Bahia, UFBA, Salvador. Endereço eletrônico: janja.araujo@uol.com.br
} 
com o planeta, consigo mesmo. O compromisso que aprendemos a ter com nosso(a) camarada de grupo, ou com os(a) mais velhos(as), precisamos aprender a ter conosco, em primeiro lugar. Aprendemos a ampliar nosso olhar sobre as coisas, sobre cada situação, sobre a vida e o mundo.

Assim, a capoeira nos possibilita pensar, também, em uma epistemologia "angoleira", a partir da qual seja possível falar sobre seus próprios processos educativos, como bem nos diz Eduardo Oliveira (2007a, p. 101):

É no movimento do corpo que vislumbro a possibilidade de uma leitura do mundo a partir da matriz africana, o que implica em decodificar uma filosofia que se movimenta no corpo e um corpo que se movimenta como cultura. $O$ corpo ancestral é a reunião desta filosofia, desta cultura bem como o resultado desse movimento de contatos e conflitos que se deram e se dá na esfera social, política, religiosa e corporal.

O corpo é aqui compreendido como lugar sagrado, expressão materializada do nosso Ser, que deve, portanto, ser cuidado, autonomamente, por cada um de nós. Mestre Pastinha nos dizia da importância de se ter cuidado com o corpo do outro, como um compromisso ético que deveria ser assumido pelos capoeiristas. Herdamos, de nossa matriz cultural africana, a intimidade com movimentos diversos do corpo, tanto na dor como no prazer. E é esse mesmo corpo, em seu movimento e em sua relação com os outros, que é capaz de formar um corpo maior, um movimento cultural, político e social.

Nesse movimento, o Axé, ou Ngunzo ${ }^{2}$ é um dos elementos fundamentais: "Axé é força vital, sem a qual, segundo a cosmovisão nagô, os seres não poderiam ter existência nem transformação". (SODRÉ, 1988b, p.129). O autor diz que essa noção de axé não se limita à cosmovisão nagô, mas também é referência ao povo Banto ${ }^{3}$ e existe nos animais, minerais, plantas, seres humanos (vivos e mortos), sendo preciso o contato de dois seres para a sua formação. Ele complementa: "sendo força, mantém-se, cresce, diminui, transmite-se em função da relação (ontológica) do indivíduo com os princípios cósmicos (orixás), com os irmãos de linhagem, com os ancestrais, com os descendentes" (SODRÉ, 1988b, p. 129).

A educação, nessa perspectiva, passa pela transmissão do Axé ou Ngunzo, corporal e presencialmente, de forma ritualizada e se caracteriza como um processo iniciático, como explica Muniz Sodré: "A ligação entre os vivos e os outros seres (mortos, animais, plantas, etc.) é iniciática. A iniciação - processo complexo de entrada do indivíduo no ciclo das trocas simbólicas" (SODRÉ, 1988b, p.128). Esses seriam alguns dos princípios da cosmovisão afro-brasileira que fundamentam a Capoeira Angola, (re)construídos nas práticas educativas cotidianas de grupos que se identificam como herdeiros de uma tradição negra e de resistência em nossa sociedade. Na perspectiva de Eduardo Oliveira (2007a, p.100), são destacados três princípios fundamentais da cosmovisão africana: diversidade, integração e ancestralidade.

Autonomia

Capoeira Angola e a construção da

"Cada qual é cada qual, e ninguém joga do meu jeito" (Mestre Pastinha).

Pedro Abib (2005) reconhece a presença marcante das matrizes culturais africanas na Capoeira Angola e aponta elementos que contribuem para compreender a sua práxis educativa para além da racionalidade moderna: a temporalidade circular e não-linear; os rituais na ligação com os aspectos míticos e sagrados, como a força vital; a oralidade, mais presente e significativa que a palavra escrita; e a memória, como "lugar" onde são guardados os saberes e conhecimentos e onde se afirma a identidade coletiva, sendo a ancestralidade fundamental na construção do imaginário do grupo. Rosângela Araújo (2004) também discute a Capoeira Angola

a autonomia, enquanto amadurecimento do ser para si, é processo, é vir a ser. Não ocorre em data marcada. É neste sentido que uma pedagogia da autonomia tem de estar centrada em experiências estimuladoras da decisão $e \quad d a$ responsabilidade, vale dizer, em experiências respeitosas da liberdade (FREIRE, 1996, p.107).

A partir desse pressuposto, o autor discorre sobre as características do processo educativo voltado para autonomia, das quais podemos destacar:

(a) a construção da curiosidade crítica, como inquietação indagadora relacionada à criatividade: "Não haveria criatividade sem a 
curiosidade que nos move e que nos põe pacientemente impacientes diante do mundo que não fizemos, acrescentando a ele algo que fazemos" (FREIRE, 1996, p. 32).

(b) O desafio que se apresenta no processo de construção da autonomia. Para Freire (1996, p. 40), uma das tarefas do educador é, "exercendo como ser humano a irrecusável prática de inteligir, desafiar o educando com quem se comunica e a quem comunica".

(c) A assunção dos educandos como sujeitos sociais e transformadores, sendo uma das tarefas mais importantes da prática educativo-crítica a de propiciar as condições em que os educandos, em suas relações uns com os outros e todos com o/a professor/a, "ensaiam a experiência profunda de assumir-se. Assumir-se como ser social e histórico, como ser pensante, comunicante, transformador, criador..." (FREIRE, 1996, p. 41).

(d) A busca pelo equilíbrio entreautoridade e liberdade, para se romper com o autoritarismo e a licenciosidade:

Um esforço sempre presente à prática da autoridade coerentemente democrática é o que a torna quase escrava de um sonho fundamental: o de persuadir ou convencer a liberdade de que vá construindo consigo mesma, em si mesma, com materiais que, embora vindo de fora de si, sejam reelaborados por ela, a sua autonomia (FREIRE, 1996, p. 93).

(e) Outra característica da prática educativa voltada para a autonomia seria a resistência, marcada pela rebeldia que não permite a resignação em face às injustiças sociais. Assim, o autor defende que é preciso que tenhamos na resistência que nos preserva vivos, na compreensão do futuro como problema e na vocação para o ser mais como expressão da natureza humana em processo de estar sendo, fundamentos para a nossa rebeldia e não para a nossa resignação em face das ofensas que nos destroem o ser. Não é na resignação mas na rebeldia em face das injustiças que nos afirmamos (FREIRE, 1996, p. 78).

Para pensarmos sobre os princípios dos processos educativos a partir da Capoeira Angola, um aspecto fundamental é compreendermos seu sentido de prática comunitária. Mestre Pastinha já nos alertava: "Camaradas, persisamos ainda de brilhantes capoeiristas que <se>unam fazendo-se colegas, reunam os seus votos mais cincerios4l que formulam o seu crecente progresso..." (DECÂNIO FILHO, 1997, p. 28).

Rosângela Araújo (2004) - a mestra Janja - destaca a importância do exercício comunitário proporcionado na prática educativa dos grupos de Capoeira Angola, e a sua relação com um aprendizado para a formação dos sujeitos, para além da "pequena roda" da capoeira:

'O exercício' da Capoeira Angola no cotidiano dos seus iniciados cumpre o aspecto filosófico que lhe é primordial: o exercício entre a Pequena e a Grande Rodas. Ou seja, embora a sua prática assegure as complexidades da individuação, é no exercício comunitário que ela é avaliada, refletida e re-avaliada, constantemente (ARAÚJO, 2004, p. 113).

Pedro Abib (2005) complementa essa perspectiva, enfatizando também a importância e a riqueza de significados da vivência comunitária no aprendizado, na perspectiva cultural africana:

$\mathrm{Na}$ perspectiva africana, como afirma Gonçalves e Silva, a construção da vida encontra um sentido maior quando relacionada à comunidade daqual faz parte o sujeito, não se restringindo ao seu aspecto individual. $\mathrm{O}$ crescimento das pessoas tem sentido quando representa fortalecimento para a comunidade a que pertencem (ABIB, 2005, p. 125).

$\mathrm{O}$ autor relaciona essa experiência, ainda, ao desafio, elemento destacado por Freire, dizendo que o aprendizado do aluno que se inicia na capoeira ocorre de forma "profundamente integrada àquela comunidade cultural, que passa então a acolhê-lo como um novo membro" (ABIB, 2005, p. 127), e acrescenta:

As situações desafiadoras da roda de capoeira se tornam então, parte do processo de aprendizagem e estão presentes, como dizem Castro Júnior e Sobrinho (2001), 'no imprevisível, no inesperado, na ginga desconcertante, no mar claro-escuro cheio de turbilhão, enfim, numa vivência inspirada e imersa na comunidade e nas histórias individuais e coletivas, mobilizadas pela memória ancestral do grupo'. O aprendizado da capoeira angola, simbolizado pela roda, tem o caráter profundamente comunitário (grifos meus).

$\mathrm{Na}$ Capoeira Angola o seu processo de aprendizagem não se limita a momentos de treinamento ou de aulas, mas passa pela inserção e o envolvimento dos aprendizes no universo da capoeiragem, o que atualmente acontece principalmente por meio dos grupos de capoeira. Os grupos, por sua vez, reconhecem-se como pertencendo à determinada linhagem, que apontam os mestres das gerações passadas aos quais os ensinamentos, filosofias e formas de trabalho de 
cada grupo se referem. No entanto, cada grupo apresenta suas peculiaridades, de acordo com seus mestres diretos e seus participantes, o que nos leva a compreender que pertencer a uma ou outra linhagem não implica necessariamente em perda de autonomia, como salienta Araújo (2004), referindose às comunidades de Capoeira Angola nas quais esses sujeitos estão inseridos:

Estas comunidades se caracterizam pela autonomia de um ajuntamento histórico, simbólico, afetivo, opcional. Aqui, não nos interessa tanto o referendo destas criações conceituais e identitárias, mas o aporte das ressignificações que lhes justifiquem a constituição do estarem juntos formando mais uma comunidade vinculada a tal matriz ou linhagem (ARAÚJO, 2004, p.138, grifos meus).

Mais um elemento para compreendermos o sentido dos grupos ou comunidades de Capoeira Angola que se identificam com a matriz cultural africana é a concepção do Ngunzo, Axé, a energia ou força vital, um "princípio-chave da cosmovisão africana", segundo Muniz Sodré (1988b, p. 87). Ele diz que "essas forças não existem (tampouco) como unidades individualizadas, isoladas, mas sempre em conexão e em exercício de influência umas sobre as outras" (SODRÉ, 1988b, p. 87). Esse sentido de interação entre as forças pode ser visto na realização dos rituais da roda de capoeira, onde a participação de cada um afeta o todo do ritual e são criadas as condições para a transmissão e "renovação" do Ngunzo. Esse princípio relacional da força é o que traz, também, o sentido de comunidade, com atenção para a importância da interrelação entre seus membros.

O exercício comunitário é aqui compreendido a partir das vivências grupais e pelo nível de envolvimento no grupo. Assim, são elementos fundamentais os valores da solidariedade e cooperação nos relacionamentos, o comprometimento com o grupo e a formação de liderança - aspectos que podem ser diretamente relacionados à característica da assunção, ou seja, com a tomada de responsabilidade sobre si, descritas por Freire em relação à autonomia. Pensando essa questão a partir da concepção de comunidade nas culturas identificadas como Arkhé, segundo Muniz Sodré (1998b), o comprometimento parece estar ligado mais a "obrigações originárias", que não dependem do indivíduo, o que pode parecer contraditório com a ideia de autonomia ou liberdade de escolha.

Araújo (2004) já levanta uma outra perspectiva em relação ao comprometimento no grupo, agora já se referindo mais especificamente à Capoeira Angola, que passa pelos exercícios de liderança, ao ressaltar que:

Entre os angoleiros todas as etapas do aprendizado (e suas promoções) são exercícios de lideranças que se iniciam no princípio do comprometimento, independentemente da obtenção de uma "autorização" para fazê-lo. Ao contrário, esta dedicação é compreendida como resultante do envolvimento e compromisso, $e$ é tida como um fundamento de avaliação permanente sobre o próprio pertencimento de cada um à comunidade (ARAÚJO, 2004, p. 133).

Com isso, podemos refletir em que medida essas comunidades podem ou não contribuir para desenvolver as características de criatividade e liberdade dos sujeitos e, ao mesmo tempo, carregar os sentidos de Força das tradições. Nesse sentido, Abib (2005, p. 151) parece também mostrar essa possibilidade, quando diz que a comunidade "tratase de uma reconstrução criativa das possibilidades de se viver e se relacionar com o mundo, com base em outros princípios e valores, pautados por uma dimensão mais solidária e humanizante".

Nas práticas pedagógicas da capoeira, nesse sentido de Comunidade, o(a) mestre(a) ou educador(a) é a maior referência, que demonstra um saber adquirido por meio de sua experiência, fundamentalmente de forma oral, seja contando histórias, fazendo reflexões durante os momentos de treinos ou em outras situações informais com os educandos, ou por meio das músicas cantadas durante as rodas. Mestre Pastinha ensina: "Os mestres rezerva segredos, mais não nega a esplicação. Você deve cantar com inredo improvisado" (DECÂNIO FILHO, 1997, p. 30).

Consideramos a oralidade de forma ampla, não apenas restrita à palavra falada, mas ao que diz respeito à vivência, à observação prática e aos exemplos de conduta. Mestra Janja diz que a Capoeira Angola, como práxis pedagógica articulada à ancestralidade, "está assentada na prática da vivência grupal e da oralidade e, como todo assentamento, impõe a ligação entre o mundo visível e o invisível, numa ética própria assegurada 
no ir e vir das múltiplas temporalidades" (ARAÚJO, 2004, p. 21. Grifos nossos).

Antes de serem criadas as "escolas" ou academias de capoeira, a sua forma de aprender era chamada "oitiva". Abib (2005, p.123) nos explica que "a oitiva constitui-se como um claro exemplo de como se dá a transmissão através da oralidade na capoeira, baseada na experiência e na observação". Às vezes, esse aprendizado acontecia "nos quintais e terreiros das casas, onde a proximidade entre o mestre e o aprendiz era um fator essencial".

Para melhor compreender esse tipo de transmissão de conhecimentos, nos valemos da distinção, apontada também por Abib (2005), citando Marilza Brito (1989), entre as chamadas sociedades do esquecimento e sociedades da memória. Nas sociedades do esquecimento, mais próximas das sociedades modernas atuais, a memória passa a ser de responsabilidade dos mecanismos e instituições (museus, escolas, meios de comunicação, computadores, etc.), que fazem o registro e arquivamento dos fatos considerados relevantes, acontecendo segundo parâmetros impostos do exterior para o interior. Nas sociedades da memória, ao contrário, apesar de co-existirem no mundo atual, sobrevivem às suas transformações, valendo-se do recurso da oralidade para buscar preservar sua cultura, como meio tradicional de transmissão da memória coletiva.

Podemos considerar, aqui, as culturas tradicionais africanas e indígenas como sociedades da memória. Nelas, os mais velhos são muito valorizados, pois representam os guardiões das tradições. Daí o provérbio iorubano que diz: "Quando morre um velho é como se uma biblioteca inteira fosse incendiada" (Hampatê Bá, apud MACHADO, 2006, p. 95).

A tradição oral é, também, a principal forma de se aprender e ensinar entre a maioria dos povos africanos tradicionais, como afirma Vanda Machado (2006, p.79):

As culturas africanas não são isoladas da vida. Aprende-se observando a natureza, aprende-se ouvindo e contando histórias. Nas culturas africanas, tudo é "História". A grande história da vida compreende a História da terra e das águas, a História dos vegetais e farmacopéia, a História dos astros, a História das águas e assim por diante... Nas culturas tradicionais africanas, a própria vida vivente era considerada também um processo contínuo de educação.

$\mathrm{Na}$ capoeira, atualmente, muito se tem registrado, utilizando-se dos recursos da escrita, em livros e pesquisas acadêmicas, de fotografias e do áudio-visual, dos meios eletrônicos e da Internet, o que influencia no processo de ensino-aprendizagem, de alguma forma. Mas encontramos ainda fortemente as características da oralidade, a valorização da relação presencial, sendo fundamental a proximidade que deve existir entre o mestre e o aprendiz. O mestre de capoeira pode, assim, guardar a característica de iniciador para a vida, como acontecia nas culturas africanas tradicionais:

O contador de história, nessa tradição, é um mestre, um iniciador da criança, do jovem e até do adulto. Trata-se de uma iniciação para a vida. As histórias míticas são contadas e recontadas e funcionam como mapas que encaminham os sujeitos nas suas possibilidades de convivência, sem prescrever conselhos, fazendo valer o arbítrio e o jeito de ser de cada um (MACHADO, 2006, p.79, 80).

Ou seja, essa forma de encaminhar para a vida deve ser respeitosa das singularidades e da liberdade, voltando-se para a autonomia dos sujeitos. No trabalho de Abib (2005, p. 124), o autor cita um trecho de uma entrevista com o Mestre Cobra Mansa, em que ele também fala sobre a importância da oralidade nas culturas tradicionais africanas:

$O$ mais importante nessa tradição é o hálito, é o que você tá passando... a sua alma que você ta transmitindo [faz o gesto como se estivesse passando a alma através da boca]. Então você não está transmitindo simplesmente a sua palavra, mas o hálito... a alma... então quando você recebe aquilo, você tá recebendo uma tradição de muitos e muitos antepassados, porque alguém já me passou isso... agora eu tô passando pra você, você vai internalizar, e depois vai poder passar a mesma coisa para o outro, então é muito mais do que você pegar o livro e ler...tem uma alma ali, tem um gesto, um olhar, tem uma forma (...) tudo isso fica marcado, porque é legal você ler um livro, mas a emoção de alguém estar te contando 
uma coisa, te passando alguma coisa, tem todo um gesto, um brilho nos olhos, que você sente uma alma sendo passada para você.

Após ler esse relato, tive a oportunidade de ouvir a mesma mensagem do Mestre Cobra Mansa durante um debate realizado com um grupo de capoeiristas, em que ele falava sobre a diferença entre a palavra escrita e falada. Ele nos chamou a atenção para o fato de ser condição para a oralidade o "estar presente". Naquele momento, as pessoas presentes na sala encontravam-se em total silêncio, apenas escutando, atenciosamente, as palavras do mestre, observando as suas expressões e sentindo a profundidade do que ele tentava transmitir. Pude sentir a diferença da qual ele falava - a partir daquele momento, as mesmas palavras que eu havia lido tomavam outro sentido para mim e se cravavam mais fortemente em minha memória. Ele citou a autora Juana Elbein dos Santos que em seu livro $O s$ Nàgô e a morte ${ }^{4}$ ele encontrou a idéia de que:

quando se fala, você não está transmitindo simplesmente a palavra, mas a sua alma. E que o que estou falando agora é o que me foi passado por pessoas, que receberam de outras pessoas, que receberam de outras pessoas, e assim por diante. $O$ que vale é a alma, que está no olhar, no gesto, no movimento (Informação verbal $)^{5}$.

Muniz Sodré também destaca a importância da oralidade, relacionando-a com a transmissão do axé, com a noção de tempo não-linear que une passado, presente e futuro e com a corporalidade, quando diz:

A transmissão do axé implica na comunicação de um cosmos que já inclui passado e futuro. Nesse processo, a palavra pronunciada é muito importante, porque pressupõe o hálito - logo, vida e história do emissor. Não tem aí vigência, entretanto, mecanismos da lógica analítica ou da razão instrumental, pois a transmissão se opera pelo deslocamento espacial de um conjunto simbólico - gestos, danças, gritos, palavras - em que o corpo do indivíduo tem papel fundamental (SODRÉ, 1988b, p.96).

No caso da capoeira, nos dias de hoje, ressalto o cuidado para não pensarmos de forma dicotômica a separação entre a "lógica analítica ou da razão instrumental" e uma lógica baseada na ontologia africana, como no caso da transmissão do axé. Devemos ainda ponderar as singularidades existentes entre as religiões de matriz africana e a capoeira. Se por um lado, vemos muitas semelhanças e a forma de transmissão do axé nos ajuda a entender a pedagogia da própria capoeira angola, vale considerar que os "mecanismos da lógica analítica ou da razão instrumental" também estão presentes em suas práticas educativas, pois fazem parte do cotidiano das pessoas envolvidas. Podemos sim reconhecer a co-existência de perspectivas diversas sobre o "educar", em que pese a valorização do corpo, como um lugar do sagrado e o poder das forças vitais, o que não implica em uma relação de interdependência entre a capoeira e a religião afro-brasileira.

A respeito dessas questões, trazemos um exemplo do campo de nossa pesquisa de mestrado, que tratou do trabalho do grupo Nzinga de Capoeira Angola com crianças e jovens da comunidade quilombola do Alto da Sereia, em Salvador/BA (MACHADO, 2012). Na ocasião do evento em comemoração aos 15 anos do grupo Nzinga, realizado na sede do grupo em São Paulo (localizada em um bairro da Zona Oeste da capital), em agosto de 2010, durante uma aula de capoeira do Mestre Poloca, ele falou sobre a possibilidade que a capoeira traz de trabalhar os diversos sentidos humanos, chamando a atenção para a necessidade de despertarmos para isso, para ampliar nossa percepção, a qual é muitas vezes desconsiderada na vida moderna. Ou seja, para aprender capoeira, é preciso utilizar amplamente a visão, a audição e o tato, ampliando-se conseqüentemente a capacidade de intuição, de forma que não seja necessário mais despender muita energia concentrando-se, por exemplo, no ritmo da música, pois com o tempo ela passa a ser "natural", intuitiva. A capoeira ensina, dessa forma, a utilizar uma atenção "multifocal", percebendo as diversas coisas que estão acontecendo ao nosso redor.

Uma característica da oralidade seria a dificuldade de se absorver a informação, por ser apenas "ouvida", não escrita, não necessária em uma avaliação escrita posteriormente. Pode-se dizer que esta questão da oralidade seria mais uma forma de se trabalhar essa atenção, como também a memória, que não significa repetição exata do que foi falado, mas a compreensão e interpretação de cada aluno. Mestre Poloca disse também que muitas informações são passadas, especialmente nos 
momentos de evento (em que há uma intensidade e concentração de atividades) e, dependendo do tempo de experiência de cada um, essas informações só poderão ser compreendidas e absorvidas no futuro, a partir da vivência na capoeira. Esse aspecto relaciona-se também à ideia de Paulo Freire que defende que o processo para se "aprender criticamente" implica que os saberes não podem ser simplesmente transferidos. "Pelo contrário, nas condições de verdadeira aprendizagem os educandos vão se transformando em reais sujeitos da construção e da reconstrução do saber ensinado, ao lado do educador, igualmente sujeito do processo" (FREIRE, 1996, p.26).

Importante aqui lembrar a noção de temporalidade, para as culturas tradicionais, em que não há a mesma distinção - linear - entre passado, presente e futuro. A oralidade está intimamente vinculada à memória cultural, que se atualiza pelas palavras dos mais antigos, quando contam histórias, bem como na realização dos rituais. Nesse sentido, nos diz Vanda Machado (2006, p.81): “A memória realiza uma "revivência" dos fatos que são atualizados pelos rituais, renovando-se e repetindose nas suas diferenças expressas em tempos e lugares. Neste sentido, a memória vai além e transcende a mera repetição".

Na perspectiva comunitária e da valorização da Ancestralidade, a figura do mestre é fundamental para garantir a oralidade no compartilhar os saberes. Abib (2005, p. 60, 61) diz:

O mestre é aquele que é reconhecido por sua comunidade, como o detentor de um saber que encarna as lutas e sofrimentos, alegrias e celebrações, derrotas e vitórias, orgulho e heroísmo das gerações passadas, $e$ tem a missão quase religiosa, de disponibilizar esse saber àqueles que a ele recorrem. $O$ mestre corporifica assim, a ancestralidade e a história de seu povo e assume por essa razão, a função do poeta que através do seu canto, é capaz de restituir esse passado como força instauradora que irrompe para dignificar o presente, e conduzir a ação construtiva do futuro.

A oralidade foi também um dos aspectos fundamentais preservados por Mestre Pastinha (assim como outros mestres de seu tempo) na forma como ensinava em sua academia, como já descrevia Valdeloir Rego, em seu ensaio sócio-etnográfico da
Capoeira Angola:

O Centro Esportivo de Capoeira Angola é o nome da academia de capoeira, fundada em 1941 por Mestre Pastinha. (Vicente Ferreira Pastinha), hoje localizada ao Largo do Pelourinho, 19, funcionando às terças, quintas, sextas-feiras às 19 horas e aos domingos às 15 horas. A sede da academia de Mestre Pastinha é um salão amplo de um casarão antigo, que também é a sede de muitas outras entidades, funcionando cada qual em horários diferentes. $O$ ensino da capoeira é feito comonas demais academias, isto é, por via oral, à exceção da de Mestre Bimba. Mestre Pastinha, como todo capoeira, vai transmitindo a seus discípulos aquilo que sabe e aquilo que quer transmitir (REGO, 1968, p. 287, 288. Grifos meus).

Nesse esforço de manutenção das tradições, acontece, ao mesmo tempo, a reconstrução dos conhecimentos por parte dos membros da comunidade. Mestre Valmir ${ }^{6}$ gosta de dizer em suas aulas de capoeira: "a função principal do mestre é ajudar os alunos a descobrirem o mestre que existe dentro de si".

O ritual da roda de Capoeira Angola apresenta-se como momento crucial, com um rico potencial para o processo educativo. Depende do envolvimento dos seus participantes para acontecer, da busca autônoma de cada um para compreendê-lo e construir seus sentidos e significados. Ou seja, o ritual implica um saber-fazer, que só pode ser apreendido por meio da experiência e da prática, junto à observação e reflexão, como diz mestre Pastinha: "todos aqueles que queira se dedicar a esse esporte, (...) deve procurar municiosamente ás regras da capoeira de angola"; para que possa falar ou dicidir com autoridade" (DECÂNIO FILHO, 1997, p. 28).

O jogo de diálogo de corpos, na roda de capoeira, pode ser comparado a uma metáfora da roda da vida. Luiz Vítor Castro Jr. diz que a relação pedagógica, na capoeira, se torna um processo educativo de ser no mundo, no mesmo sentido da concepção da práxis educativa, uma vez que:

A capoeira acaba por ser uma escola da vida, onde se aprende a jogar capoeira. E, ao aprender a jogar capoeira, aprende-se também a jogar na roda do mundo, a tomar 
posição, analisar circunstâncias de classes sociais com interesses antagônicos, interferir no sentido de querer transformar a realidade. Todavia, esta pedagogia se dá no campo fértil da práxis, em que capoeiristas e sociedade formam uma unidade dialética (CASTRO, 2003, p. 146).

$\mathrm{O}$ ritual da capoeira "instaura um mundo paralelo, em relação direta com uma nova cosmogonia que é recriada através das construções simbólicas referentes ao tempo mítico primordial". Não somente na capoeira, mas na maioria das manifestações tradicionais, o ritual é de suma importância, pois, "é o ritual que permite essa transposição do aqui e do agora para tempos imemoriais, para locais sagrados, onde tudo se originou. É o ritual que permite a conexão com o sagrado, com a arché..." (ABIB, 2005, p. 63).

Pastinha provavelmente teve grande sensibilidade em relação a esses sentidos do ritual da capoeira. Pires (2002, p.78) argumenta que um dos elementos formadores da Capoeira Angola mais trabalhado por Mestre Pastinha talvez tenha sido o ritualístico. Ele se preocupa com o que chama de "regras" da capoeira, ou seja, a forma como deve acontecer o ritual, e dá atenção especial à sua musicalidade $^{7}$, que entendemos como o elemento principal para fazer a relação com os ancestrais. $\mathrm{O}$ que traz a energia e a inspiração necessária para o fluir de um "autêntico" jogo de capoeira é o ritmo da música.

Chamo para esta roda novamente Muniz Sodré, que descreve o ritual como um "espaçotempo fundador (porque veicula uma força irredutível à identidade histórica dominante), aberto ao jogo de uma comunicação pluralista, voltada para as relações humanas no presente". Ele destaca a importância da "trama do quotidiano vivido no aqui e agora do grupo que interessa à cosmovisão negra" (SODRÉ, 1988a, p. 102), mostrando o potencial de luta dessas comunidades, em defesa e valorização do legado deixado pelas culturas negras, historicamente excluídas em nossa sociedade pelas elites dominantes. Luta que é também pela pluralidade, em respeito às diferenças, abarcando, portanto, pessoas das diversas identidades étnicoraciais, de gênero ou idade.

É na participação no ritual da roda que cada um(a) vai se forjando capoeirista, angoleiro(a), construindo-se, encontrando-se, no jogo de desequilíbrio para se equilibrar, de desconstrução para se formar. "A capoeira angola não tem propriamente um método. Se o tem, é o da desconstrução. Constrói-se para destruir e destrói-se para construir. Ela desconstrói até mesmo suas próprias referências e seu aprendizado é, na verdade, uma desconstrução de si" (OLIVEIRA, 2007, p. 177). E como já dizia mestre Pastinha: "Capoeira Angola é mandinga de escravo em ânsia de liberdade. Seu princípio não tem método e seu fim é inconcebível ao mais sábio capoeirista”. Essa falta de métodos sistematizados, de regras claras, o aprender fazendo, vendo, sentindo, aprender os mistérios e segredos, causa vertigem.

A vertigem que a cultura do simulacro evidencia é ritualizada de modo que o desequilíbrio possa ser usado como arma e não como fraqueza. A arte do desequilíbrio que a Angola desenvolve é a arte de tornar possivel o que parece ser impossível; é a arte de viver apesar da adversidade; é a arte do negaceio; é a mandinga; é a capoeira (OLIVEIRA, 2007a, p. 326).

É essa arte que os muleekes e muleekas do grupo Nzinga vão aprendendo na roda, para levar para suas vidas. $\mathrm{Na}$ roda, eles(as) ocupam papel fundamental para que o ritual aconteça: a formação da bateria, que garantirá um bom ritmo para o ritual e a ligação com a Força Vital, o Ngunzo. E são cobrados(as) pelo(as) mestre(as) e alunos(as) para cumprirem o seu papel. Tudo isso faz parte do movimento da Semiótica do Encantamento de "Por-se-a-si-mesmo-como-valioso", o que implica "auto-conhecimento e alter-conhecimento: conhecimento-de-si exige reconhecer a ancestralidade; conhecimento-do-outro exige recorrer à identidade" (OLIVEIRA, 2007a, p. 183). A identidade pensada a partir da alteridade permite que cada um perceba seu próprio valor, singular, reconhecendo sua ancestralidade, e respeite o outro, em suas diferenças.

$\mathrm{Na}$ primeira vez em que fui a uma roda de capoeira do grupo Nzinga, em Salvador, fiquei encantada com aqueles(as) muleekes(as), com a forma como eles e elas tocavam, cantavam e jogavam na roda, com a força de sua presença ali. A ponto de aquele grupo ficar conhecido pelas "suas crianças" (e jovens) e elas representarem parte fundamental do grupo e para a qualidade da música e da energia que envolve os que ali se encontram presentes.

Esta é uma característica marcante nas rodas do grupo Nzinga: a participação efetiva das 
crianças, como capoeiristas e protagonistas. Inclusive tocando o berimbau gunga (o instrumento responsável pela coordenação da roda, geralmente tocado pelo mestre ou peloaluno mais antigo no grupo), não simplesmente para garantir sua participação por serem crianças, mas porque já se mostram capazes de cumprir tais funções e ali encontram espaço e estímulo para assumir esse papel e aprender a fazê-lo. É por meio da sua participação no ritual, semanalmente, que as crianças vão aprendendo como ele deve acontecer e os sentidos que ele carrega, seja observando os adultos ou as crianças mais velhas, seja pelas palavras dos mestres, ou ainda, por meio da relação que fazem com suas vivências nos rituais do candomblé, para aqueles que estão envolvidos na religião.

Assim acontece com o ritual: ele se repete, é modelo de retorno e religação com o divino, e, ao mesmo tempo em que possui toda uma hierarquia que dita as formas como deve acontecer, ele também estimula a criatividade. A referência à hierarquia e aos fundamentos considerados de tradição no ritual apresenta o limite entre liberdade e libertinagem e entre autoritarismo e autoridade. A autoridade do mestre se justifica por ser o mais antigo, portanto responsável por garantir que o ritual mantenha essa "força mítica", essa religação ancestral, assumindo, assim, o papel de educador.

A criatividade, assentada na tradição, pode ser vista na ludicidade, expressividade e teatralidade que devem compor o jogo da capoeira, onde os corpos estão em uma situação em que podem se expressar mais livremente doque no cotidiano. Os princípios como o desafio, a espontaneidade e a autoconfiança, citados por Freire, são imprescindíveis, ao mesmo tempo em que há toda uma obediência às "regras" ou aos "fundamentos" do ritual, como tanto defendeu Mestre Pastinha. Mais uma vez, o ritual pode contribuir para a noção de limite (contrapondo-se à licenciosidade), a partir do respeito aos seus fundamentos ou princípios, que definem a forma com que ele deve ser organizado. Esses fundamentos se justificam pela relação com a ancestralidade, que traz o sentido maior ao ritual.

Lembremos, porém, que "cada qual é cada qual" e cada roda tem sua singularidade. A ligação com a mandinga ${ }^{8}$ e a espiritualidade pode fortalecer a pessoa a se assumir como capoeirista e a conquistar autonomia dentro de um grupo. Mestra Janja enfatizou, em relato feito ao seu grupo, que as crianças devem assumir-se como capoeiristas, não como "crianças jogando capoeira", estimulando esse tipo de atitude e de sentimento mais autônomo por parte delas. Indo na mesma direção, Pedro Abib afirma que:

A lógica diferenciada e diferenciadora desse processo permite que os capoeiras sejam sujeitos de sua própria ação, na medida em que no jogo, durante o ritual da roda, o indivíduo tanto aprende quanto ensina num rico processo de interação social, em que o improviso, o inusitado, o desafio, o "estar atento" são elementos constitutivos de formas diferenciadas de aprendizagem no jogo de capoeira, com base nos princípios de oralidade (...). Uma frase do mestre Pastinha que ficou famosa, foi aquela que diz: 'cada qual é cada qual, e ninguém joga do meu jeito' (ABIB, 2005, p. 142. Grifos meus).

A Ancestralidade nos remete a uma dessas coisas que se encontram nas profundezas de nossos Ser nos (re)ligando ao nosso "natural".

Sopro 9

Atente os seus ouvidos

Mais às coisas que aos Seres

À voz do Fogo, fique atento,

Ouça a voz das Águas.

Ouça através do Vento

A Savana a soluçar

É o Sopro dos ancestrais...

A referência à ancestralidade diz de quem somos nós, a quem devemos a nossa existência aqui e agora, mas vai além de laços consanguíneos, trazendo seu sentido para o pertencimento. Implica em conhecer e reconhecer-se na construção de sua própria história e missão de vida. A ancestralidade remete não ao passado descolado do presente e do futuro, mas a partir da ideia do tempo circular, nãolinear. Ela remete ao reconhecimento dos valores e sentidos que nos conformam, que dão sentido à nossa auto-percepção no mundo, ao autoconhecimento, à compreensão mais ampla de nossa própria existência. Ancestralidade que envolve a dimensão espiritual, passando pelo corpo e pela natureza.

Oliveira (2007a) explica que a ancestralidade tornou-se e difundiu-se como categoria analítica, que supostamente se refere à tradição da África tradicional, para interpretar as várias esferas da vida do negro brasileiro, principalmente na religião - sendo o candomblé o 
tema central de seu trabalho. E mostra como não se restringe aos negros, incluindo qualquer grupo racial que se identifique com a "africanidade":

Legitimada pela "força" da tradição, a ancestralidade é um signo que perpassa as manifestações culturais dos negros no Brasil, esparramando sua "dinâmica" para qualquer grupo racial que queira assumir a identidade de "africano". Passa assim a ser a portadora autentica de uma "lógica" africana que organiza a vida de seus adeptos - brancos ou negros - e engendra estruturas sociais capazes de manter $e$ atualizar os "valores africanos" forjados na África pré-colonial (OLIVEIRA, 2007a, p. 23).

Ele traz a ideia de uma "África mítica”, que não apresenta necessariamente semelhanças significativas com a África contemporânea, uma vez que se trata de um vasto continente, que abriga uma diversidade de povos e culturas, muitos deles vivendo em uma realidade distante das tradições da África pré-colonial.

Esta busca pela re-construção de uma história negada e pela oportunidade de pensar o mundo desde um lugar mais próprio e antihegemônico, resulta numa ação positiva e produz uma narrativa e um sistema de identificação inclusivos. $\mathrm{O}$ que não impede de reconhecer as culturas como processos dinâmicos de significação, nas quais não há uma essência.

No caso do grupo Nzinga de Capoeira Angola, a questão político identitária do negro brasileiro é posta como uma bandeira de luta, que defende essa ligação intrínseca da capoeira com suas matrizes africanas. Sabemos que essa não é uma situação de unanimidade dentre os diversos grupos de capoeira, que seguem ideologias diferentes e muitas vezes opostas. Mas podemos perceber, a partir dessa perspectiva da ancestralidade, que o reconhecimento da "africanidade" na capoeira, assim como no candomblé, não significa negar que ela vem sendo constantemente (re)criada no Brasil, pois se trata, mais, de uma posição política que luta pela valorização desta que se reconhece como "cultura negra" no Brasil, diante da história de discriminação que ainda se faz presente em nossa sociedade. Assim, o conceito de Ancestralidade não se refere a um passado congelado no tempo, mas é constantemente (re)construído e (re)significado nas práticas cotidianas dos grupos ou comunidades. E os rituais são fortes veículos para tal.

$\mathrm{O}$ (a) mestre(a) é, novamente, a figura responsável pela preservação da memória coletiva. Vanda Machado (2006, p. 107), referindo-se a Hampatê Bá, destaca a figura do Doma, entre os povos Iorubá, o qual "é considerado o guardião dos segredos da Gênese cósmica e das ciências da vida e mestre de si mesmo". Ela conta que:

Antes de iniciar as histórias do seu povo, ele evoca os ancestrais com todo respeito, dizendo-lhes o que pretende falar com seus ouvintes. Quando se trata de transmitir conhecimentos, ele o faz considerando os conhecimentos mais antigos, o conhecimento tradicional como uma cadeia de transmissão onde, segundo a tradição, ele é apenas o contador. (...) As primeiras palavras do Doma servem para evocar a presença dos seus antepassados, para pedir-lhes que venham assistir a sua história para que sejam evitados equívocos. Isto porque o africano acredita que o ancestral não se afasta de sua família nem da sua comunidade quando morre. Na verdade, a palavra, para muitos africanos, tem poder de realização; é sopro, vida, força (MACHADO, 2006, p. 107, 108).

No início das rodas de Capoeira Angola também evocamos os ancestrais ao cantar a "chula" ou "louvação", louvando o sagrado, os ancestrais, os mestres que nos possibilitaram aprender a capoeira:

Iê, viva meu Deus

Iê viva meu mestre

Iê a todos mestres

Iê a capoeira

Iê que é de Angola

Iê, que é de Angola, camará!

A louvação é cantada não apenas em memória e homenagem aos grandes mestres do passado (lembrando que este passado é ainda recente, em torno de apenas um século atrás). Louvamos também os Orixás, Inquices, a Deus, os elementos da natureza e a sua (nossa) essência espiritual. É um momento em que cada um pode se concentrar em suas próprias crenças e espiritualidade, agradecendo e pedindo sua proteção. As músicas da capoeira são também um elemento fundamental de relação com a 
ancestralidade e a oralidade, sendo os nomes e as histórias dos antigos mestres sempre lembradas, principalmente nas ladainhas ${ }^{11}$.

Mestra Janja, em sua tese, discute sobre as formas de manutenção das tradições na Capoeira Angola e a importância da referência ao pertencimento a determinada "linhagem" de mestres, porém defende que esse pertencimento não é - nem deve ser - contrário ao fortalecimento da autonomia dos sujeitos que seguem tais ensinamentos. Ela diz que esses sujeitos

tornam-se responsáveis pala manutenção do conhecimento estruturado sobre os pilares da ancestralidade e oralidade, e a busca das definições necessárias à produção e seleção de valores que atuem como "alimentos" necessários ao fortalecimento não apenas do corpo físico, mas a própria cadeia de pertencimento, sendo protagonistas da sua permanência e autonomia (ARAÚJO, 2004, p. 97).

\section{Fechando esta Roda}

$\mathrm{Na}$ figura seguinte, estão destacadas as categorias principais aqui referenciadas, compreendendo-se que essas categorias coexistem, de forma interconectada, sendo essa relação dinâmica, em movimento constante, circular e espiral.

Figura 1: Capoeira Angola: Cultura Negra de Libertação

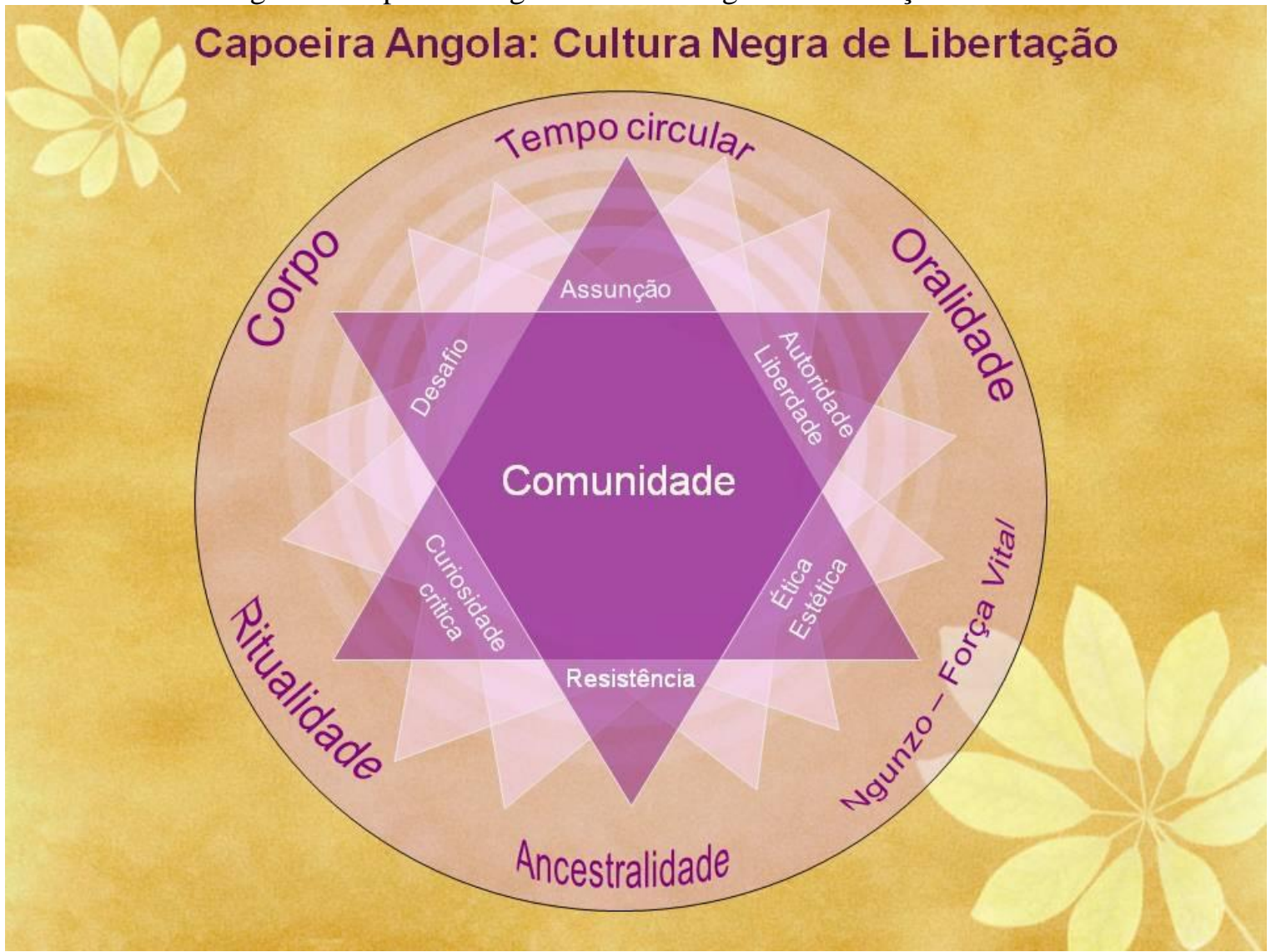

Fonte: MACHADO, 2012

Circulando por fora da estrela, estão conceitos mais diretamente relacionados à Capoeira Angola em sua relação com a chamada cosmogonia africana no Brasil; e na parte de dentro da estrela estão categorias voltadas à autonomia, sendo esses elementos importantes para pensarmos criticamente as práxis educativas da Capoeira Angola. Cada uma dessas categorias envolve uma diversidade de outros elementos, de forma complexa e dinâmica. Sem a pretensão de esgotar a diversidade do real, a intenção éapenas focar em alguns aspectos-chave para o olhar aqui proposto.

A comunidade é elemento central, uma vez que traz a dimensão das relações, remetendo às 
dinâmicas do grupo, a forma como as atividades são organizadas, às relações entre aluno(a)-mestre(a) ou educador(a)-educando(a). A vivência em comunidade representa a forma possível para o movimento de preservação e atualização das tradições e constitui-se como a base para a efetivação dos processos de transmissão de saberes. A comunidade é que permite que os princípios como a memória, a oralidade, a ancestralidade e a ritualidade, "possam ser enfatizados de maneira a garantir que os processos de aprendizagem social dos sujeitos se realizem com base na cultura e nas tradições daquele grupo social" (ABIB, 2005, p. 150). É na vivência em comunidade que encontramos, portanto, os demais elementos aqui trabalhados como parte do processo educativo na Capoeira Angola.

O desafio, a curiosidade crítica, a assunção como ser social-transformador, a relação autoridade-liberdade, ética e estética e a resistência, características eleitas para se pensar a Autonomia, por sua vez, também dependerão de como essa comunidade se conforma, de como se dão as relações entre seus pares e como as pessoas dão significado às suas práticas.

$\mathrm{O}$ que mantém o grupo/comunidade conectado à ancestralidade é a repetição, frequente, do ritual. Ele faz a ligação entre a ancestralidade e a comunidade, por meio da oralidade, passando pelo corpo, que possibilita transmitir a Força Vital e integrar passado, presente e futuro, em uma temporalidade circular. A ritualidade cuida por manter a forma "tradicional" da realização dos rituais e, ao mesmo tempo, por re-criar, atualizando, materializando essa tradição no "aqui e agora". A comunidade faz a ligação entre a pequena e a grande roda - aprender os fundamentos do ritual (sobre ancestralidade) para agir no mundo, "daqui para frente", entendendo que "passado, presente e futuro" são partes de um mesmo processo, que é dinâmico e circular (assim como a própria roda).

A ancestralidade, por sua vez, é o solo comum. É o elemento que prepara o solo, onde se planta a cresce a comunidade. Mas nada cresce sem a Força Vital, sem Ngunzo. Elemento de ancestralidade que precisa estar plantado, no solo onde se constitui a comunidade. A forma de transmitir os insumos - ou os saberes - necessários para que essa comunidade cresça e se fortaleça é a oralidade, que acontece em presença, corporificada, por força da palavra, falada, mas também cantada ou simplesmente gestualizada.

A capoeira angola atua no mundo pelo encantamento. E fundamenta-se na Ancestralidade. Capoeira que acontece no ritual - a Roda - onde sua estética reflete sua ética. Onde se encontram o velho e novo, atualizam-se os antepassados, circula-se o Ngunzo, restituindo-se a Força Vital. Rituais que são realizados pelas comunidades que formam os grupos de Capoeira Angola.

\section{Notas}

1 Trecho retirado do vídeo-documentário "Mestre Pastinha: uma vida pela capoeira".

2 "GUZO (banto) ( $L S)$-s. força, axé. Cf. gorô. Kimb. nguzu." (CASTRO, 2005, p. 245).

3 Muniz Sodré (1988b, p.85, 86), diz que "o valor supremo dos bantos é 'vida, força, viver fortemente ou força vital'. Assegurar o fortalecimento da vida ou a transmissão da força de vida à posterioridade é objetivo explícito de muitas práticas ritualísticas".

4 SANTOS, Juana Elbein dos. Os Nàgô e a morte: Pàde, Àsèsè e o culto Ègun na Bahia. Petrópolis: Vozes, 3. ed., 1984.

5 Fala durante debate realizado na Associação de Capoeira Angola Navio Negreiro (ACANE), coordenado por Mestre Renê, após exibição do filme Atlântico Negro, durante evento em comemoração à semana da consciência negra. Salvador, 18 nov. 2010.

6 Mestre da Fundação Internacional de Capoeira Angola - FICA-BA.

7 Assim como outros mestres dessa época, como o próprio mestre Bimba e Waldemar - exímios tocadores de berimbau e cantadores.

8 "Originalmente, a palavra mandinga, ou melhor, mandingo - como aqui ficaram conhecidos os malinkes - designava um povo africano islamizado oriundo da África Ocidental. Famosos, segundo Bastide, por serem grandes feiticeiros e mágicos. Não foi à toa que o termo mandinga acabou se popularizando como sinônimo de feitiço. No tempo da escravidão, mandinga ou feitiço eram as práticas mágicas dos escravos, em especial os preparos de ervas e venenos usados pelos negros para matar seus senhores. (...) $\mathrm{Na}$ capoeira, além de ser um jogo de malícia, de trucagem, considerada uma das armas mais fortes do capoeirista, é também a magia do capoeira que tem o corpo fechado, que faz reza forte, e traz a proteção dos orixás. Fora isso, a mandinga ainda tem uma função estética, ela embeleza o jogo da Capoeira, aparece como uma representação teatral. É a malemolência do corpo do jogador que 
ao som do berimbau traz leveza à luta, o sorriso traiçoeiro, o golpe não previsto, a brincadeira de capoeira" (DIAS, 2006, p.17-18). Podemos dizer que a mandinga seria um dos aspectos dessa herança africana na capoeira, portanto presente em suas marcas ancestrais, como uma das importantes armas de luta, que disfarça a força do mais fraco contra sua situação de opressão.

9 Poema de Birago Diop, em tradução de Leo Gonçalves. Disponível em: <http://revistamododeusar.blogspot.com/2011/06/ birago-diop-1906-1989.html>. Acesso em 07 jun. 2011

10 Os cantos, na roda de Capoeira Angola, são identificados como: ladainha (canto inicial, que geralmente conta uma história ou passa uma mensagem, que não tem resposta do coro), chula ou louvação (saudando os/as mestres/as, os antepassados, a capoeira, etc. Nesse momento não se joga, apenas se escuta o canto) e corrido (cantigas mais curtas que a ladainha, são respondidas pelo coro e enquanto são cantadas os jogadores jogam na roda).

11 A ladainha corresponde ao canto de abertura do ritual, cantada no início da roda e pode ser novamente cantada se, por algum motivo, o(a) mestre(a) pára a roda, seja para dar algum recado ou para reorganizar o ritual, cantando uma outra ladainha quando reinicia a roda. A ladainha pode falar de histórias antigas da capoeira, de seus(suas) mestres(as) e mitos antepassados, de mensagens de aviso para os jogadores, mensagens de contestação ao sistema, dentre outros.

\section{Referências}

ABIB, Pedro R J. Capoeira Angola: Cultura Popular e o jogo dos saberes na roda. Campinas: CMU/Unicamp / EDUFBA, 2005.

ARAÚJO, Rosângela Costa. Iê, Viva me Mestre: a Capoeira Angola da 'escola pastiniana'como práxis educativa. Tese (Doutorado) - Faculdade de Educação, Universidade de São Paulo, São Paulo, 2004.
DECÂNIO FILHO, Ângelo. A herança de Pastinha. 2. ed. Salvador: Coleção São Salomão, 1997.

DIAS, Adriana Albert. Mandinga, Manha $e$ Malícia: uma história sobre os capoeira na capital da Bahia (1910-1925). Salvador: EDUFBA, 2006.

LUZ, Marco Aurélio. Agada: dinâmica da civilização africano-brasileira. Salvador: Centro Editorial e Didático da UFBA, Sociedade de Estudos da Cultura Negra no Brasil, 2000.

MACHADO, Sara Abreu da Mata. Saberes $e$ Fazeres na Capoeira Angola: a Autonomia no jogo de muleekes. Dissertação (Mestrado) - Faculdade de Educação, Universidade Federal da Bahia, Salvador, 2012.

MACHADO, Vanda. Tradição Oral e Vida Africana e Afro-brasileira. In: SOUZA, Fiorentina, LIMA, Maria Nazaré. Literatura Afro-brasileira. Salvador: Centro de Estudos Afro-Orientais, 2006.

OLIVEIRA, Eduardo David de. Filosofia da ancestralidade: corpo e mito na filosofia da educação brasileira. Curitiba: Editora Gráfica Popular, 2007a.

Ancestralidade na Encruzilhada. Curitiba: Editora Gráfica Popular, 2007b.

PASTINHA, Vicente Ferreira (Mestre Pastinha). Quando as pernas fazem mizerer. Manuscritos e desenhos de Mestre Pastinha. Disponível em: $<$ http://portalcapoeira.com/Downloads/Download-d ocument/155-Capoeira-Angola-por-Mestre-pastinha >. Acesso em: 15 mar. 2011.

REGO, Valdeloir. Capoeira Angola: ensaio sócioetnográfico. Salvador: Ed. Itapuã, 1968.

SODRÉ, Muniz. A verdade seduzida: por um conceito de cultura no Brasil. 2. ed. Rio de Janeiro: Francisco Alves, 1988a.

$O$ terreiro e a cidade: a forma social negro-brasileira. Rio de Janeiro: Vozes, 1988b.

\section{Sobre as autoras}

Sara Abreu da Mata Machado é capoeirista, educadora e musicista. Atualmente, vem realizando a pesquisa de doutorado "Baobá na Encruzilhada: Ancestralidade, Capoeira Angola e Permacultura", junto ao Programa de 
Doutorado Multi-Institucional e Multidisciplinar em Difusão do Conhecimento (DMMDC / UFBA 2012/2016). Possui mestrado em Educação pela Universidade Federal da Bahia, no qual realizou a pesquisa: "Saberes e Fazeres na Capoeira Angola: a Autonomia no Jogo de Muleekes". É integrante do grupo Griô: Culturas Populares, Diáspora Africana e Ancestralidade. Suas pesquisas abordam a Capoeira Angola relacionada as temáticas da ancestralidade, cultura negra, educação, relações raciais e de gênero e permacultura.

Rosângela Costa Araújo é Professora Permanente do Doutorado Multi-institucional e Multidisciplinar de Difusão do Conhecimento/DMMDC-UFBA e do Programa de Pós-Graduação em Estudos Interdisciplinares sobre Mulheres, Gênero e Feminismo (PPGNEIM), coordenadora do Núcleo de Estudos Interdisciplinares sobre a Mulher - NEIM/UFBA. É mestra de Capoeira Angola e fundadora-coordenadora do Instituto Nzinga e Estudos da Capoeira Angola e Tradições Educativas Banto no Brasil/INCAB. Tem trabalhos na área de Educação, com ênfase em administração de sistemas educacionais, atuando principalmente na interface dos estudos sobre raça, gênero, cultura e desenvolvimento. Também desenvolve pesquisas sobre ações afirmativas em educação e cultura afro-brasileira, com foco nos estudos sobre capoeira e religiões de matrizes africanas.

Recebido em junho de 2015.

Aprovado em setembro de 2015. 